Western University

Scholarship@Western

2018

Pedagogical approaches to the teaching and learning of formulaic language

Ana Pellicer-Sánchez

Frank Boers

fboers@uwo.ca

Follow this and additional works at: https://ir.lib.uwo.ca/edupub

Part of the Applied Linguistics Commons, and the Language and Literacy Education Commons

Citation of this paper:

Pellicer-Sánchez. A., \& Boers, F. (2018). Pedagogical approaches to the teaching and learning of formulaic language. In A. Siyanova-Chanturia \& A. Pellicer- Sánchez (Eds.), Understanding formulaic language: A second language acquisition perspective (pp. 153-173). Routledge. 
This is the pre-final version of:

Pellicer-Sánchez. A., \& Boers, F. (2018). Pedagogical approaches to the teaching and learning of formulaic language. In A. Siyanova-Chanturia \& A. Pellicer- Sánchez (Eds.), Understanding formulaic language: A second language acquisition perspective (pp. 153-173). Routledge.

\section{Pedagogical approaches to the teaching and learning of formulaic language}

Ana Pellicer-Sánchez and Frank Boers

\section{Introduction}

The surge in vocabulary studies 20 years ago led to a greater interest in examining the effectiveness of different procedures for the teaching and learning of lexical items. These investigations have often been categorized into two main approaches: examinations of incidental learning and interventions to engage learners in intentional or deliberate learning. Incidental learning accrues as a by-product of a communicative activity, without a particular intention to learn language items or linguistic features (Schmitt, 2010). Lexical items acquired when learners are reading a book, listening to an interview on the radio, or watching a movie are all examples of what has been considered incidental vocabulary learning, because the primary focus during these activities is on content rather than on the linguistic packaging of that content. By contrast, intentional vocabulary learning involves a deliberate effort to commit lexical items to memory or to consolidate knowledge of items, as for instance when studying word lists, testing oneself using flashcards, or completing vocabulary exercises. In actual practice, it is hard to tell whether a given learner might be focusing temporarily on new words also during an activity such as reading a story. Consequently, it is far from easy to operationalize the distinction between incidental and intentional learning. What is possible, however, is to distinguish between learning conditions that are and are not intended to engage learners in intentional learning. Following Nation and Webb (2011), we will consider a vocabulary learning condition to be intentional if learners are forewarned of a vocabulary test and/or if task instructions explicitly direct their focus to lexical items. Intentional and incidental approaches are not mutually exclusive. Instead, they complement one another. For instance, incidental learning conditions (e.g., extensive reading) may be particularly beneficial for the fine-tuning and consolidation of newly acquired knowledge. For example, repeated contextualized encounters with a word that was first studied deliberately as a discrete item may not only entrench this item more firmly in memory but also foster familiarity with facets of the word that are possibly less amenable to deliberate study, such as its phraseological behaviour.

The vast majority of studies empirically testing the efficiency of particular activities for vocabulary learning have focused on the acquisition of single-word items. However, as illustrated in this volume, a high proportion of language is formulaic, and knowledge of multiword lexis or "formulaic sequences" (FSs) (Wray, 2002) is essential for achieving high levels of proficiency in 
a second language (L2) (e.g., Crossley, Salsbury, \& McNamara, 2015; Durrant \& Schmitt, 2009; Kremmel, Brunfaut, \& Alderson, 2017; Stengers, Boers, Housen, \& Eyckmans, 2011). There is now a growing consensus not only among researchers but also among authors of pedagogyoriented books that attention to formulaic language (FL) should be an integral part of language pedagogy (Lewis, 1993; Lindstromberg \& Boers, 2008a). The last decade has witnessed an unprecedented increase in the number of "intervention" studies examining the teaching and learning of FL, and the findings of these studies have the potential to inform pedagogical practice. The aim of this chapter is to provide a concise (and, of necessity, non-exhaustive) review of available empirical research to date.

The chapter is organized roughly along the traditional categories of incidental and intentional learning conditions, but we will recognize an additional category - that of semi-incidental learning conditions. These semi-incidental conditions are characterized by steps which direct learners' attention to particular FSs in a text (and thus potentially raising their awareness of phraseology more generally), while the learners are nonetheless expected to engage with the text first and foremost for its content. A prominent example is a reading comprehension task using a text where the visual saliency of certain lexical items has been enhanced typographically. As this typographic enhancement is intended to incite learners to shift their attention from text content to the wording of that content, we consider this intervention different from "purely" incidental learning conditions. At the same time, when no instruction to study the target items is given, it is an intervention that does not fully qualify as intentional learning (as defined previously) either. We will therefore situate this and similar interventions between the realms of incidental and intentional learning conditions.

Let it be clear that this review focuses on studies intended to gauge the effectiveness of tried methods and procedures for helping learners acquire multiword lexis. Due to constraints of space, the review does not provide coverage of the several laudable efforts made in recent years to compile lists of high-utility multiword expressions that merit prioritization in teaching and learning (e.g., Martinez \& Schmitt, 2012; but see Durrant, this volume). Also outside the scope of this review is the creation and validation of a growing number of print and online resources for learners' independent exploration of the phraseological dimension of language (but see Cobb, this volume, and Meunier, 2012).

\section{Incidental learning of formulaic language}

Learners can increase their lexical repertoire by picking up words and expressions from reading texts, listening input, audio-visual materials, and through interaction. Among these, reading has attracted the most attention from vocabulary researchers, but the focus has long been on single words, with FSs a relatively new addition to this strand of research.

Studies on the acquisition of single words have shown that incidental vocabulary learning is influenced by features of the target items themselves, such as word class (Kweon \& Kim, 2008); characteristics of the input materials in which target words are embedded, as for instance the presence of pictorial support (e.g., Bisson, Van Heuven, Conklin, \& Tunney, 2015), the provision 
of annotations (e.g., Chun \& Plass, 1996), and the helpfulness of contextual cues (Webb, 2008); the learners' familiarity with the topic (e.g., Pulido, 2007); the learners' general proficiency level (e.g., Tekmen \& Daloglu, 2006); and the learners' vocabulary knowledge in particular (Horst, Cobb, \& Meara, 1998). Among the many factors, however, frequency of encounters with the same words has perhaps received the most attention from vocabulary researchers. A reliable estimate of the number of encounters required for word acquisition could help to gauge the chances that words beyond the high-frequency bands will be acquired, taking into account differing amounts of exposure (Nation, 2014). Unfortunately, while several studies have shown that more encounters with the same words tend to result in better gains, such estimates of the number of encounters necessary for successful acquisition range widely, from six (Rott, 1999) and eight (e.g., Horst et al., 1998) to more than 10 (Pigada \& Schmitt, 2006; Pellicer-Sánchez \& Schmitt, 2010; Webb, 2007). This range is perhaps not so surprising, as the effect of frequency of exposure is almost bound to interact with other factors, such as the semantic relevance, formal salience, and distribution of the instances of the given word (e.g., Laufer \& Rozovski-Roitblat, 2015; Szudarski \& Carter, 2016; Webb \& Chang, 2015).

Still, frequency clearly matters, and consequently this factor also figures high on the research agenda concerning the incidental acquisition of multiword lexis. An early example is an experiment by Durrant and Schmitt (2010), who examined English as a Second Language (ESL) learners' acquisition of adjective-noun collocations (e.g., excellent drink) presented in sentences which the participants were asked to read aloud. The learners were assigned to one of three experimental conditions: (1) target collocations embedded in a sentence once; (2) repeated exposure to the same sentences containing the target collocations (i.e., verbatim repetition); or (3) repeated exposure to the target collocations in different sentences (i.e., varied repetition). Post-test results showed that both repetition conditions outperformed the single exposure condition. Interestingly, repetition in the same contexts led to stronger memories of the target collocations than repetition in different sentence contexts.

It may be argued that a sentence-level task as used in Durrant and Schmitt (2010) is rather different from the reading of "texts". A study which did use texts and which also found an effect for frequency was conducted by Webb, Newton, and Chang (2013). English as a Foreign Language (EFL) learners read short stories for about 35 minutes while listening to the audio-recording of these stories. Eighteen target verb-noun collocations (e.g., break the silence; raise questions) were incorporated into these texts, and participants read one of four versions of the texts, which varied in the number of instances of each target collocation (just once, 5, 10, and 15 times). Post-test results showed a significant effect of repetition and that multiple encounters with an FS are necessary for substantial learning to occur. A single encounter did not bring about noticeable learning at all, and for the majority of the learners as many as 10 encounters turned out insufficient for them to accurately recall the complete FSs.

Compelling evidence for the role of frequency was not found in a conceptual replication by Pellicer-Sánchez (2017) and Pellicer-Sánchez and Siyanova-Chanturia (under review), however. Participants in these studies read one of two versions of a short story that differed in the number of instances of target collocations - four versus eight instances. Results showed a significant 
increase in collocational knowledge with both versions, but no statistically significant difference in learning gains between them. As the authors acknowledge, the nature of the target collocations used in their experiments (i.e., collocations containing a pseudoword) needs to be borne in mind when interpreting the results, because the novelty of the pseudoword is likely to catch a reader's attention. In many cases, a learner will encounter a collocation consisting entirely of familiar words (e.g., have an accident), and, since familiar words attract little attention (Godfroid, Boers, \& Housen, 2013), it is conceivable that their combination in a wordstring will go unnoticed, too. Approximate replications with real collocations would therefore be useful.

In sum, the findings suggest that, reminiscent of what was found for uptake of single words, frequency of encounters with FSs certainly matters, but it is only one of several variables that influence the likelihood of uptake. Other variables probably include characteristics of the expression itself (e.g., degrees of formal complexity, novelty, and semantic transparency), its relevance for text comprehension, the availability of counterparts in the learners' first language (L1), and individual differences among learners (e.g., level of proficiency). The nature of the text and the distribution of the instances of target items may also matter.

From a pedagogical perspective, it is worth bearing in mind that the learning gains attested in aforementioned studies such as Webb et al. (2013) resulted from reading modified materials that were densely packed (or "seeded") with instances of the same expressions. Non-manipulated authentic texts are extremely unlikely to expose readers to, for example, as many as 15 instances of the same collocation in a short time span (as was the case in one of Webb et al.'s reading conditions). For example, Boers and Lindstromberg (2009) screened 120 pages of a popular novel (a detective story) for instances of verb-noun collocations (e.g., tell + truth) and found that almost none of these occurred more than once, and none occurred often enough to come close to the frequencies associated with learning in aforementioned reading experiments (also see Cobb, this volume, for discussion). It therefore would take large amounts of unmodified input to foster incidental acquisition of many FSs, and even so, certain types of FSs might just not occur the required number of times for considerable learning to occur.

Next to frequency of encounters, another recurring theme in incidental vocabulary acquisition research has been modality of input. Studies have furnished evidence that vocabulary acquisition from listening input occurs as well (e.g., Brown, Waring, \& Donkaewbua, 2008; Van Zeeland \& Schmitt, 2013; Vidal, 2011), but also that the gains tend to be smaller than from reading (Brown et al., 2008; Vidal, 2011). To our knowledge, the acquisition of L2 multiword lexis from audio input alone has been investigated in only one study so far. Webb and Chang (under review) compared the learning of FSs in three input conditions: reading, reading while listening, and listening. Their college EFL learners read, listened to, or read-while-listened to a graded reader containing 17 target sequences in six sessions over a three-week period. Post-test results showed that reading while listening had an advantage over both reading-only and listening-only conditions. An explanation for the added value of listening input when it comes to helping learners pick up FSs from texts may lie with prosody (Lin, 2012; this volume). Prosody can aid the parsing of text because it often signals where the boundaries of semantic units are, and this can thus be expected to help learners identify such units, including multiword expressions. 
If bi-modal input is more conducive to incidental acquisition of FSs than silent reading alone, then one may wonder whether multi-modal input, such as captioned videos, might also be comparatively beneficial. Research has already pointed to the usefulness of multi-modal input for single-word acquisition (Montero Perez, Van Den Noortgate, \& Desmet, 2013, for a metaanalysis), and so it is definitely worth investigating whether this extends to the acquisition of FSs. A classroom experiment on incidental uptake of FSs from multi-modal input was conducted by Hoang and Boers (2016). High-intermediate ESL learners twice read and listened to a story supported by pictures, and they were told in advance that they would be asked to retell the story. Announcing this output task was deemed to prompt engagement with lexis used in the story that the learners might anticipate using to retell the story. The story contained a large number of FSs, but only a minute fraction of these (less than 7\%) were recycled accurately in the learners' versions. By comparison, the learners did recycle most of the content words from the text. One explanation for their comparatively elusive nature could simply be that FSs are often longer than single words and thus more challenging to hold in (phonological) short-term memory. Another is that not all FSs are easy to decipher let alone to pinpoint their pragmatic function, and so learners may develop some receptive knowledge of such expressions but stay wary of using them productively (Dagut \& Laufer, 1985). Yet another explanation is the lack of attention that precise wording attracts when texts are processed "naturally", i.e., when texts are processed with a focus on content rather than the linguistic packaging of that content (Van Patten, 2002). To address this issue, some pedagogy-minded applied linguists (e.g., Sharwood-Smith, 1993) have proposed to typographically enhance selected language features in texts, so as to make these perceptually more salient. That is the type of intervention we turn to next.

\section{Semi-incidental learning of formulaic language}

Successful incidental vocabulary learning is subject to learners' noticing of the lexical items in the input. The role of attention was emphasized by Schmidt (2001) in his Noticing Hypothesis. As he claims, "people learn about the things they attend to and do not learn much about the things they do not attend to" (p. 30). However, learners do not always notice unknown lexical items in the input (Laufer, 2005). This need for attention, together with the often small gains reported by incidental learning studies, has led vocabulary researchers to explore techniques to direct learners' attention to words in the input. One of such methods is pre-modifying the input through inputenhancement techniques (Ellis, 2015). In vocabulary learning, this input-enhancement is usually done by means of typographic enhancement (e.g., highlighting items in text by means of underlining, bold typeface, italics, uppercase, or use of colour).

Most studies on the effect of enhancement techniques have focused on the learning of grammatical forms, though (e.g., Jahan and Kormos, 2015; Winke, 2013). Fewer studies have examined their effect on vocabulary learning, and, when the intervention did concern vocabulary, it was typically used to signal to the reader that glosses or annotations were available for the highlighted words (e.g., Hulstijn, Hollander, \& Greidanus, 1996; Laufer, 2005; Peters, Hulstijn, Sercu, \& Lutjeharms, 2009). 
Typographic enhancement of FSs may address one of the practical issues raised earlier in the section about incidental acquisition. While it increases the likelihood that learners will attend to the relevant word strings, it does not require the same resourcefulness on the part of the materials designer as "input flooding", i.e., inserting multiple instances of the same expression in a text (e.g., Pellicer-Sánchez, 2017; Webb et al., 2013). A recent study by Boers, Demecheleer, He, Deconinck, Stengers, and Eyckmans (2017), for example, presented learners with texts that were only manipulated by underlining FSs that were already present in them. The learners were found more likely in a post-reading test to recognize FSs from the texts if these had been typographically enhanced. Another recent study, by Szudarski and Carter (2016), compared the effect of input flooding alone with the effect of input flooding combined with typographic enhancement of the target collocations, and found that the latter condition led to greater learning gains.

While these studies support the hypothesis that typographically enhanced FSs attract attention, online reading measures can provide more direct evidence. Choi (2017) investigated the effect of typographic enhancement (bold typeface) on the processing and learning of L2 collocations. Participants were asked to read a text containing a set of target collocations in either an enhanced or unenhanced version while their eye movements were tracked. Not only did post-reading tests show an advantage for the enhanced version, but the eye-movement measures also showed that collocations in the enhanced version attracted more and longer fixations than the same collocations in the unenhanced version of the text. Worth mentioning is that the learners who had read the enhanced version of the text were found less successful at remembering segments from the text untouched by the enhancement than their peers who had read the version without any enhancement at all. A similar "trade-off" in learners' intake of enhanced and unenhanced phrases from a text was reported in the aforementioned study by Boers et al. (2017), where the enhancement of a small number of FSs led to particularly successful post-reading recognition of precisely these sequences but also an apparent reduction of these learners' intake of other sequences which had been left untouched in the text. It is perhaps to be expected that students will interpret enhancement as an effort on the part of the teacher/materials designer to signal the most important elements of a text, and so it is not so surprising they will focus less on what is left unenhanced. Similar concerns have been expressed about such side effects of typographic enhancement in the area of grammar acquisition research (Lee and Huang, 2008).

More studies involving typographic enhancement of FSs are available, but these will be reviewed further later because they involve intentional learning as well. Before we turn to intentional learning conditions, however, it is worth mentioning that FSs can also be made more salient in aural input. "Aural enhancement" is not uncommon in interactional feedback, for example, when a teacher uses prosodic cues to make particular language elements more perceptually salient (e.g., Nassaji, 2016, for a review of the research on interactional feedback). To the best of our knowledge, the effectiveness of prosodic enhancement for the purpose of FS acquisition in particular is as yet unexplored (but see Lin, this volume, for the potential benefits of intonation units for FS acquisition). 


\section{Intentional learning of formulaic language}

So far, our review has mostly concerned learning conditions where texts are manipulated with a view to increasing the likelihood of FS uptake. Crucially, however, the initiative lies with the learners as to whether they actually attend to and cognitively engage with the target FSs in manipulated texts. The interventions we discuss in the present section are ones where FSs are presented to learners more explicitly as objects of language study and where the intention of the activity is clearly to learn these items. We consider roughly three ways of creating these intentional learning conditions: (1) instructions to explore texts for the presence of FSs; (2) decontextualized FS-focused activities not necessarily linked to any input text; (3) engaging learners with particular characteristics of FSs that can render these more memorable.

It is worth mentioning that several of the studies we review here include comparisons of an intentional learning condition with an incidental and/or semi-incidental condition of the kinds discussed previously. In that regard, this line of investigation is reminiscent of comparisons conducted in the domain of single-word acquisition, such as Laufer's (2005) comparison of the effectiveness for word learning of (a) exclusively meaning-focused activities (which we have called incidental learning conditions), (b) activities with a focus on words as the need arises during primarily meaning-focused activities (akin in some ways to what we have labelled semi-incidental learning conditions), and (c) activities where words are presented as objects for language study (i.e., intentional learning conditions - the focus of the present section). As Laufer points out, this parallels the distinction originally made by Long (1991) in the realm of L2 grammar learning between "meaning-focused", "form-focused", and "forms-focused" activities.

\section{Intentional learning of formulaic language from texts}

We now turn to interventions where learners are instructed explicitly to engage with the phraseological dimension of texts, and which therefore belong to the realm of intentional learning as we defined it. An early investigation into the merits of such interventions was conducted by Boers, Eyckmans, Kappel, Stengers, and Demecheleer (2006). Two groups of EFL learners used the same in-class reading and listening texts in the course of a school year. One group was regularly asked to identify useful phrases in these texts, an activity - "text chunking" - advocated by Lewis (1997). The other group was not explicitly alerted to the phraseological dimension of the texts. At the end of the course, the students' oral proficiency was gauged in an interview. The text-chunking group was found to use more FSs than the comparison group. However, the greater number of FSs found in the utterances produced by the chunking group did not actually reflect greater uptake of these from the texts they had explored in class. Instead, the FSs used in the interview were mostly expressions "mined" from a text given as prompt for part of the interview. So, it seems the intervention equipped the students with a strategic advantage, but it is far from clear to what extent the text-chunking activities alone helped the students expand their repertoire of FS for active use in real-time communication. When the study was partially replicated with a new cohort of students, but without the use of an L2 text prompt in the end-of-course interview, again no compelling evidence emerged that students in the chunking group had added a greater number of FS to their 
repertoires than those in the comparison group (Stengers, Boers, Housen, \& Eyckmans, 2010). It needs to be acknowledged, though, that an interview is probably too crude an elicitation instrument to reveal the true extent to which particular items were learned from texts spread over a whole course.

Peters (2009) conducted a shorter but more tightly controlled experiment using a post-test targeting precisely those lexical items included in a reading text. A number of lexical items were typographically enhanced and glossed. One group of EFL learners was simply instructed to focus on new vocabulary, while the second group was instructed explicitly to pay attention to collocations. Both groups showed substantial learning gains, but there was no clear effect of the instruction to pay special attention to collocations. It is likely that both groups engaged with the collocations to the same extent because of the enhancement in the text. Peters (2012) conducted a conceptual replication of her earlier study, this time with two groups of learners of L2 German. A number of words and FSs were typographically enhanced in a text, and these also came with a gloss. Other items were also glossed, but they were not enhanced in the text. On the post-test, the students performed better on the target items that were enhanced in the text (which adds to the body of evidence for the effectiveness of enhancement when it comes to FSs). As in the earlier study, one group of students was explicitly briefed beforehand about the importance of FSs. Again, however, this group did not perform noticeably better on the post-test items targeting the FSs than did their peers in the comparison group.

A number of studies have investigated the added value of "output" activities that require learners to recycle the FSs they have focused on in an input text. In Szudarski (2012), for example, intermediate learners were asked to read a short story containing verb-noun collocations. Participants were assigned to one of three conditions: reading only, reading followed by exercises on collocations from the text, and a control condition. Test results showed that the addition of exercises helped learners to acquire collocational knowledge at both receptive and productive levels. By contrast, the reading-only condition did not lead to much measurable learning. It is worth mentioning, though, that the verb-noun combinations in this study contained de-lexicalized verbs, which seem to be particularly problematic for L2 learners due to their lack of semantic distinctiveness and often due also to the non-congruency with L1 counterparts (Peters, 2016). Laufer and Girsai (2008) took a special interest in such non-congruency between L1 and L2 collocations, and investigated whether translation exercises might be a particularly beneficial addition to a reading activity. Three groups of EFL students read the same text containing as-yetunfamiliar collocations (e.g., hit the headlines). Explicit steps were taken to clarify the meaning of these to the students. One group was subsequently asked to discuss the contents of the text and to debate a moral dilemma it raised. The second group did multiple-choice and completion exercises concerning the target collocations (but without involving comparisons with L1). The third group was given translation exercises, which naturally involve L1 to L2 comparisons. In both an immediate and a delayed post-test, the latter group performed best and the group which had not done any vocabulary-focused exercises performed the poorest. It is perhaps worth mentioning that the post-test format chosen in this study - a translation test - may have given an edge to the students who had practiced the target items through translation exercises over those who had been given the collocation-focused exercises that bore less resemblance to the test format. 
These studies by Szudarski (2012) and Laufer and Girsai (2008) evaluated the benefits of particular procedures in "one-off" experiments. To inform pedagogic decisions at the level of course design, however, it is also important to gauge the effects of a more sustained focus on FL throughout a course, involving various activities around FSs encountered in texts. Jones and Haywood (2004) describe an EAP course in which the students were regularly engaged in activities with a focus on FSs. While the authors found clear evidence that these students' awareness of FL increased, their actual use of FSs in their end-of-course essays did not differ markedly from that of a comparison group that had not received the FS-focused treatment. In a conceptual replication, Peters and Pauwels (2015) also examined the effect of integrating various FS-focused activities in an EAP course. They found evidence of an effect, but this evidence emerged much more clearly in an FSfocused recognition test than through the learners' spontaneous use of FSs in their end-of-course writing assignments. This illustrates again that it may take a lot of productive practice with newly learned FSs for learners to spontaneously and adequately deploy this knowledge in communicative tasks. The need to provide many opportunities for learners to consolidate knowledge to the extent that it becomes readily retrievable (i.e., "procedural") is fully recognized in the field (e.g., Gatbonton \& Segalowitz, 2005; Wood, 2009).

Finally, a considerable amount of studies have explored the use of corpora as the input text for learning FSs. These data-driven learning (DDL) approaches usually set a task that involves learners working with corpus data. These conditions would also be considered intentional approaches of the sort covered in this section. However, since these are discussed in depth elsewhere in this volume (see Chapter 10), we refrain from reviewing them here.

\section{Decontextualized exercises on formulaic language}

Several studies have investigated conditions for the learning of FSs that bypass their introduction through textual input. This has been done, for example, to compare the outcomes of incidental, semi-incidental, and intentional learning of collocations, as in a study by Sonbul and Schmitt (2013), who compared the outcomes of learning of collocations under three conditions: (1) reading a passage with multiple instances of the target collocations embedded; (2) reading the passage with the same target collocations typographically enhanced; (3) studying the target collocations as decontextualized items. Post-test results showed that reading enhanced text and studying decontextualized items both brought about more noticeable learning gains than the "purely" incidental learning condition.

Some experiments have compared different FS-focused study procedures with a view to evaluating what knowledge is engendered by these procedures. Webb and Kagimoto (2009) asked EFL learners to either read three example sentences containing the same verb-noun collocation (e.g., sit exams) or to copy the same collocation three times in gapped sentences. A series of post-tests revealed no overall difference in effectiveness between the two conditions. On the test format where the learners were prompted to recall the complete collocations, the overall success rate was under $30 \%$. This is arguably a poor learning outcome given the time invested. If so, this may be due to the absence of any retrieval effort - the collocations were available for copying throughout 
the study procedure (see Karpicke \& Roediger, 2008, for a review about the importance of retrieval practice in learning). A study by Alali and Schmitt (2012), for example, reported slightly better outcomes when learners completed gap-fill exercises by retrieving targets from memory than when they were asked to chorally repeat target collocations 10 times. A case for using more than a single study procedure is made by Zhang (2017), who assigned EFL learners to one of three learning conditions: (1) simply studying verb-noun collocations (e.g., bear resemblance); (2) inventing sentences incorporating the given collocations on display; and 3) a combination of both procedures. A control group only took the pre-test and the post-tests. The overall scores on the tests clearly indicate that the combined study procedure resulted in the greater gains. This outcome needs to be put into perspective, though, because the overall success rate obtained under this procedure was still only $35 \%$ better than what was attested in the control group. Again, it may be argued that, because the collocations were available to the students, the element of retrieval was missing from the study procedure. In a study with idioms as targets for learning, Stengers, Deconinck, Boers and Eyckmans (2016) also found that a copy exercise contributed very little to learners' retention of the expressions.

Giving participants the task to study FSs presented in a decontextualized fashion (i.e., not embedded in a text) can also help determine factors about the FSs "themselves" (rather than contextual variables) that make them relatively easy versus difficult to learn. For example, in an investigation where EFL learners were asked to study a list of idioms, Steinel, Hulstijn, and Steinel (2007) found that imageability (i.e., the ease with which an expression calls up a mental image) was one of the predictors of learning success. In another example of this line of research, Peters (2016) demonstrated that non-congruency with L1 counterparts hinders learning of collocations even when they are studied deliberately. How FSs are grouped together for deliberate study matters as well. Webb and Kagimoto (2011), for example, found that learning sets of adjective-noun collocations where the adjectives bear semantic resemblance (e.g., narrow escape and slim chance; tall order and high spirits) is much harder than learning the same collocations grouped in ways that minimize the risk of inter-item confusion. This is reminiscent of what has been found repeatedly in relation to grouping semantically related words together (e.g., Erten and Tekin, 2008).

Given that most of the studies we have reviewed so far in this chapter are framed in one way or another as initiatives to help inform pedagogical practice, it is rather surprising that very few studies to date have explicitly taken as a point of departure how FSs are actually tackled in mainstream language education, as reflected, for example, in popular commercially available course books and textbooks. One exception is a study by Boers, Demecheleer, Coxhead, and Webb (2014), who first identified exercise formats for practicing verb-noun collocations that are commonly used in EFL textbooks and then put these to the test in classroom experiments. Many of the exercise formats were variants of matching operations where the collocation is broken up into its constituent parts, and the challenge for the learner is to re-assemble them (e.g., in a gapfill exercise where the missing verb is to be supplied to match the given noun collocate). Often a number of choices are presented to the learner (e.g., do/give/make + a suggestion), and the task is to discriminate between the correct choice and the lures. The learning gains in the several trials reported in Boers et al. (2014) turned out discouragingly poor: delayed post-test scores were typically just $5-10 \%$ better than the pre-test scores. In many cases, the students erroneously 
reproduced the lures they had contemplated (and sometimes chosen) while doing the exercises, although corrective feedback was given at the end of each exercise. In an approximate replication, Boers, Dang, and Strong (2017) found that this risk of inter-item confusion was minimized by a gap-fill exercise format where the collocations (to be chosen from) are kept intact from the start.

What is striking about many textbook exercises on FSs is that they rely on learning through trial and error. Boers et al.'s (2017) analysis of 323 exercises found in a corpus of 10 EFL textbook series revealed that more than half of these do not present users with examples of the targeted FSs (such as collocations) prior to or alongside the exercise. Unless the learner already knows the expressions, doing these exercises inevitably amounts to a fair amount of guesswork, and it seems the textbook authors rely on teachers' corrective feedback to override memories of wrong choices. The data from the classroom experiments reported in Boers et al. (2014) and Boers et al. (2017) suggest, however, that wrong responses made in a collocation exercise do risk leaving undesirable traces in memory, and that these may compete for selection when the learner later tries to retrieve the right expression. If so, then it is probably judicious to minimize the risk of error at the exercise stage. One way of doing this is to present learners with exemplars of the target expressions alongside the exercise, as is done in some resources for independent study, such as McCarthy and O'Dell (2005). Stengers and Boers (2015) compared this exemplar-guided implementation of a gap-fill exercise on Spanish verb-noun collocations with a trial-and-error implementation and found the former to be slightly more beneficial. At the same time, the learning gains attested for that condition in a delayed post-test were far from spectacular either (18\%).This again suggests that practice without any retrieval effort should not be expected to work wonders.

Using exemplars is also a core feature of approaches known as data-driven learning (DDL), often associated with the use of corpus tools such as concordances. However, as that rapidly expanding area merits a chapter of its own (Cobb, this volume), we shall refrain from discussing it here.

\section{Making formulaic language memorable}

The interventions reviewed so far involve steps to expose learners to multiple instances of selected FSs, to increase the salience of those FSs in texts, to prompt learners to imitate or reproduce FSs they have been presented with, to give learners feedback on FSs they have generated, and to engage learners in the exploration of sets of exemplars. Generally absent from such interventions are attempts on the part of the teacher or materials designer to engage learners with facets of the target FSs that may render them memorable. Two such facets have received a fair amount of attention from applied linguists.

The first applies mostly to figurative idioms and concerns steps to connect their (abstract) idiomatic meaning (e.g., take a back seat $=$ allowing someone else to take control and make the important decisions) to a literal reading of the expression (e.g., one can take a back seat in a car and thus leave the driving to someone else) (e.g., Boers, Demecheleer, \& Eyckmans, 2004; Boers, Eyckmans, \& Stengers, 2007). Sometimes learners can presumably make these associations autonomously, but for many idioms it helps if learners are at least pointed in the right direction. Such resuscitation of a literal reading is likely to lend concreteness and imageability to the 
expression, and - in keeping with Dual Coding theory (e.g., Paivio, 1986) - this is believed to benefit memory. In a similar vein, figuratively used prepositional and phrasal verbs can be made more imageable by pointing out the metaphors that underpin them (e.g., Boers, 2000). For instance, the use of out in find out can be made sense of if one realizes that "seeing" is often equated with "knowing" (hence expressions such as "I see what you mean" and "I'm still in the dark about it") and that taking something "out" of a container will make it visible. A substantial number of studies have furnished empirical support for such steps that make idioms and prepositional/phrasal verbs more memorable by evoking their literal underpinnings (Boers, 2013, for a review).

The second facet of FSs that may be exploitable for the purpose of memorability is their sound patterning. A pattern that has attracted a fair amount of attention in recent years is alliteration (cut corners; slippery slope; time will tell; toss and turn; good as gold; life-long learning; better safe than sorry), whose incidence in various segments of English phraseology by far exceeds statistical chance. For example, approximately $17 \%$ of expressions listed in English idiom dictionaries display alliteration (Boers \& Lindstromberg, 2009). A series of experiments with ESL and EFL learners has shown that alliterative FSs tend to enjoy a small advantage over non-alliterative matched controls in recall tests, but crucially also that this advantage is enhanced quite substantially when learners' attention is directed to the presence of alliteration (e.g., Boers, Lindstromberg, \& Eyckmans, 2014; Eyckmans, Boers, \& Lindstromberg, 2016; Lindstromberg \& Boers, 2008b). It is likely that similar effects of attention-directing can be obtained with FSs that exhibit rhyme (e.g., steer clear; brain drain; left high and dry) or assonance (e.g., small talk; cook the books; hit and miss) (e.g., Boers et al., 2014b; Lindstromberg \& Boers, 2008c). Of particular interest here from a practical perspective is that it takes very little investment of time or effort for a teacher to point out a pattern such as alliteration in an expression so as to unlock its full mnemonic potential. Considering the conspicuous presence of alliteration in English phraseology, it is rather surprising to find no attempts in EFL textbooks to exploit it in some way.

\section{Conclusions and future directions}

In this chapter, we have reviewed diverse studies examining interventions intended to accelerate acquisition of L2 FSs. The interventions range from manipulating input texts to the use of "mnemonics". We have characterized the conditions for FS learning created in the interventions as incidental, semi-incidental, and intentional, while recognizing that these distinctions are not always easy to make. We have sometimes made evaluative comments concerning the amount of learning observed in the studies. There is an ongoing debate in the realm of L2 vocabulary research about the relative contributions of incidental and intentional learning conditions. It is generally accepted that intentional approaches bring about noticeable gains at a faster rate (e.g., Laufer, 2003; Lin \& Hirsh, 2012). However, Nation and Webb (2011) argue that this needs to be put into perspective because incidental learning conditions, such as extensive reading, provide additional opportunities for skills development (such as reading comprehension and reading fluency) beyond the acquisition of a pre-selected set of new words. The effectiveness of treatment conditions is typically evaluated by comparing outcomes specifically concerning a narrow set of pre-selected targets (such as a pre-selected set of FSs), but this may overlook the possibility that learners in a 
comparison condition who did not fare so well on that specific front benefited from their treatment in other ways that fell outside the scope of the test measures (Boers, 2015).

In any case, comparisons of the relative effectiveness of incidental and intentional approaches to FS learning across studies will inevitably lack validity due to the many differences involved (type and number of target FSs, participant profiles, type and timing of tests, amount of time on the activity, etc.). The closest to a valid comparison are studies where incidental and intentional learning conditions were assessed within a single research endeavour, such as Sonbul and Schmitt (2013). What is nonetheless safe to say after inspecting the body of evidence on incidental FS uptake from exposure is that it tends to require multiple encounters with new FSs in a relatively short time span for measurable learning to happen. It is important to reiterate that evidence of incidental learning of new FSs emerged in these studies only when texts were "seeded" with sufficient numbers of instances of the target FSs - and what number is sufficient is likely to depend on circumstances (including the nature of the FSs, their dispersion in the text, the learners' proficiency level, and the modality of the text input). As pointed out, it is quite unlikely for the same FSs to occur multiple times in an authentic (i.e., non-manipulated) text, and so it would seem that the chances of "purely" incidental uptake by L2 students will ultimately depend on whether practitioners or material writers are prepared to embark on the laborious process of creating the kind of textual input that was used in some of the studies on incidental learning of collocations that we have reviewed here. If this is not realistic, it does by no means follow that authentic texts make no contribution to FS learning. As hinted in the introduction to this review, any incidental encounter with an FS that was intentionally focused on some time previously has the potential to further entrench it in memory and to help the learners fine-tune their appreciation of its usage patterns. Incidental learning is likely to be incremental, and the gradual deepening and refinement of knowledge over time is something that the offline test measures used in most studies almost inevitably fail to capture. In future research it may therefore be worth investigating (e.g., by means of eye-tracking) how brief prior intentional study of lexical items such as FSs influences learners' reading behaviour as they re-encounter the items during content-focused reading, and to compare learning outcomes from this to a reading condition with input flooding.

If intentional learning of FSs is expected to yield noticeable gains faster than incidental learning, this needs to be qualified, too. As our review shows, intentional learning procedures can vary widely in their degrees of effectiveness. For example, mere copying of FSs, without any requirement for learners to try and retrieve the items from memory, did not appear to be a particularly powerful learning practice. Neither did matching-type exercises commonly used in contemporary course books seem effective. The effectiveness of any pedagogical procedure - be it incidental, intentional, or both - will inevitably depend on the quality of its design and how it is implemented.

A part of this review concerned studies on the benefits of attention-drawing techniques such as typographic enhancement. These "semi-incidental" learning conditions seem to hold good promise - they were generally found to lead to better uptake of FSs than "purely" incidental conditions, and they may even be a match for FS-focused exercises (Sonbul \& Schmitt, 2013), although it is clear that much more research is needed to confirm this theory. The benefits of typographic 
enhancement have been interpreted as being a direct consequence of increased attention to the target lexical items. Eye-tracking data, providing an online record of learners' attention to enhanced input, have confirmed this assumption (Choi, 2017). The practical advantage of typographic enhancement is that it is very easy to implement - easier than input flooding although selecting items for enhancement is not straightforward. Teachers who wish to enhance FSs in a text may need familiarity with resources such as online corpus tools to be able to ascertain that the targets they are selecting actually are FSs and ones deserving of their students' attention. It may also be worth recalling that the increased attention usurped by enhanced text elements can be in detriment of text comprehension and of intake of other potentially useful language from the text. Future research should take advantage of the benefits of eye-tracking as a direct measure of learners' attention to vocabulary items and use it in combination with explicit vocabulary tests, to gain a richer and more accurate picture of the effect of different attention-grabbing techniques on learners' noticing of FL and the subsequent learning. So far, research on enhancement of FSs has focused exclusively on written text. The effect of other types of enhancement techniques, such as auditory input manipulation, remains to be explored.

We have for convenience's sake used "formulaic sequence" (Wray, 2002) as an umbrella term in this review. A downside of using an umbrella term is that it risks concealing the diversity of the phenomenon at hand. Different FSs pose different challenges for learners and may therefore require different pedagogical intervention to help learners meet these challenges. In several of the studies reviewed here, "collocation" serves a similar umbrella function and has been used to characterize word partnerships regardless of semantics. For pedagogical purposes, however, in particular with a view toward putting oneself in the learner's shoes, recognizing a difference between what have "traditionally" been called collocations and idioms may be useful (Boers \& Webb, 2015), with collocations being comparatively easy to comprehend (if one knows the meaning of the constituent words) and idioms being harder to figure out due to their "noncompositionality" (in the sense that the meaning of the expression does not follow straightforwardly from adding up the meanings of the constituent words). For example, while there have been interesting attempts at exploring the role of frequency in incidental learning conditions, it stands to reason that the effect of frequency is modulated by other factors, and the semantic nature of the target items is likely to be one of them. Yet, it must be possible to take this factor into consideration (see Boers, Lindstromberg \& Webb, 2014, for an example of a very modest attempt at an exploration of this kind). After all, many of the studies reviewed here used a variety of test measures, including ones that gauge uptake of form and ones that gauge uptake of meaning. It may be worth (re-)examining such test data more closely at the item level, because this may help determine what sort of learning condition benefits the learning of what sort of FS and what aspects of knowledge about certain FSs are privileged by a certain learning condition. Given the complexity and the multifaceted nature of the phenomenon at hand, a one-size-fits-all approach to the learning and teaching of FL is very unlikely to be tenable.

A final comment concerns the pedagogical orientation of the strand of research we have reviewed here. If, ultimately, the aim is to inform pedagogical practice, then one must wonder if it might not be useful to find out more systematically how teachers and course designers around the world are already addressing the challenge of FL learning. Unfortunately, little is known (apart from what is 
reflected in commercially available manuals and textbooks) about the materials and procedures intended for FS learning that are used in "real" classrooms (and L2 learning environments more generally). If applied research wishes to inform pedagogical practice, a legitimate question to ask is whether that research should not also be informed by the current realities of pedagogical practice, at least so as to prioritize those questions on the research agenda that matter the most to educational practitioners and to their learners.

\section{References}

Alali, F., \& Schmitt, N. (2012). Teaching formulaic sequences: The same or different from teaching single words? TESOL Journal, 3(2), 153-180.

Bisson, M-J., Van Heuven, W., Conklin, K., \& Tunney, R. (2015). The role of verbal and pictorial information in multi-modal incidental acquisition of foreign language vocabulary. Quarterly Journal of Experimental Psychology, 68(7), 1306-1326.

Boers, F. (2000). Metaphor awareness and vocabulary retention. Applied Linguistics, 21(4), 553571.

Boers, F. (2013). Cognitive Linguistic approaches to second language vocabulary: Assessment and integration. Language Teaching, 46(2), 208-224.

Boers, F. (2015). Weighing the merits of form-focused intervention. Language Teaching Research, 19(3), 251-253.

Boers, F., Dang, C. T., \& Strong, B. (2017). Comparing the effectiveness of phrase-focused exercises. A partial replication of Boers, Demecheleer, Coxhead, and Webb (2014). Language Teaching Research, 21(3), 362-280.

Boers, F., Demecheleer, M., Coxhead, A., \& Webb, S. (2014). Gauging the effects of exercises on verb - noun collocations. Language Teaching Research, 18(1), 54-74.

Boers, F., Demecheleer, M., \& Eyckmans, J. (2004). Etymological elaboration as a strategy for learning figurative idioms. In P. Bogaards \& B. Laufer (Eds.), Vocabulary in a second language: Selection, acquisition and testing (pp. 53-78). Amsterdam and Philadelphia: John Benjamins.

Boers, F., Demecheleer, M., He, L., Deconinck, J., Stengers, H., \& Eyckmans, J. (2017). Typographic enhancement of multiword units in second language text. International Journal of Applied Linguistics, 27(2), 448-469.

Boers, F., Eyckmans, J., Kappel, J., Stengers, H., \& Demecheleer, M. (2006). Formulaic sequences and perceived oral proficiency: Putting a lexical approach to the test. Language Teaching Research, 10(3), 245-261.

Boers, F., Eyckmans, J., \& Stengers, H. (2007). Presenting figurative idioms with a touch of etymology: More than mere mnemonics? Language Teaching Research, 11(1), 43-62. 
Boers, F., \& Lindstromberg, S. (2009). Optimizing a lexical approach to instructed second language acquisition. Basingstoke: Palgrave Macmillan.

Boers, F., Lindstromberg, S., \& Eyckmans, J. (2014a). Is alliteration mnemonic without awareness-raising? Language Awareness, 23(4), 291-303.

Boers, F., Lindstromberg, S., \& Eyckmans, J. (2014b). When does assonance make L2 lexical phrases memorable? The European Journal of Applied Linguistics and TEFL, 3(1), 93-107.

Boers, F., Lindstromberg, S., \& Webb, S. (2014). Further evidence of the comparative memorability of alliterative expressions in second language learning. RELC Journal, 45(1), 8599.

Boers, F., \& Webb, S. (2015). Gauging the semantic transparency of idioms: Do natives and learners see eye to eye? In R. Heredia \& A. Cieslicka (Eds.), Bilingual figurative language processing (pp. 368-392). Cambridge: Cambridge University Press.

Brown, R., Waring, R., \& Donkaewbua, S. (2008). Incidental vocabulary acquisition from reading, reading-while-listening, and listening. Reading in a Foreign Language, 20(2), 136-163.

Choi, S. (2017). Processing and learning of enhanced English collocations: An eye-movement study. Language Teaching Research, 21(3), 403-426.

Crossley, A. S., Salsbury, T., \& McNamara, D. S. (2015). Assessing lexical proficiency using analytic ratings: A case for collocation accuracy. Applied Linguistics, 36(5), 570-590.

Chun, D. M., \& Plass, J. L. (1996). Effects of multimedia annotations on vocabulary acquisition. The Modern Language Journal, 80(2), 183-198.

Dagut, M., \& Laufer, B. (1985). Avoidance of phrasal verbs - A case for contrastive analysis. Studies in Second Language Acquisition, 7(1), 73-79.

Durrant, P. \& Schmitt, N. (2009). To what extent do native and nonnative writers make use of collocations? International Review of Applied Linguistics, 47, 157-177.

Durrant, P., \& Schmitt, N. (2010). Adult learners' retention of collocations from exposure. Second Language Research, 26(2), 163-188.

Ellis, R. (2015). Understanding second language acquisition. Oxford: Oxford University Press.

Erten, I. H., \& Tekin, M. (2008). Effects on vocabulary acquisition of presenting new words in semantic sets versus semantically unrelated sets. System, 36(3), 407-422.

Eyckmans, J., Boers, F., \& Lindstromberg, S. (2016). The impact of imposing processing strategies on L2 learners' deliberate study of lexical phrases. System, 56, 127-139.

Gatbonton, E., \& Segalowitz, N. (2005). Rethinking communicative language teaching: A focus on accuracy and fluency. Canadian Modern Language Journal, 61(3), 325-353. 
Godfroid, A., Boers, F., \& Housen, A. (2013). An eye for words: Gauging the role of attention in L2 vocabulary acquisition by means of eye-tracking. Studies in Second Language Acquisition, 35(3), 483-517.

Granger, S. (1998). Prefabricated patterns in advanced EFL writing: Collocations and formulae. In A. P. Cowie (Ed.), Phraseology: Theory, analysis, and applications (pp. 145-160). Oxford: Oxford University Press.

Hoang, H., \& Boers, F. (2016). Re-telling a story in a second language: How well do adult learners mine an input text for multiword expressions? Studies in Second Language Learning and Teaching, 6(3), 513-535.

Horst, M., Cobb, T., \& Meara, P. (1998). Beyond a clockwork orange: Acquiring second language vocabulary through reading. Reading in a Foreign Language, 11(2), 207-223.

Hulstijn, J. H., Hollander, M., \& Greidanus, T. (1996). Incidental vocabulary learning by advanced foreign language students: The influence of marginal glosses, dictionary use, and reoccurrence of unknown words. Modern Language Journal, 80(3), 327-339.

Jahan, A., \& Kormos, J. (2015). The impact of textual enhancement on EFL learners' grammatical awareness of future plans and intentions. International Journal of Applied Linguistics, 25(1), 4666.

Jones, M., \& Haywood, S. (2004). Facilitating the acquisition of formulaic sequences: An exploratory study. In N. Schmitt (Ed.), Formulaic sequences (pp. 269-300). Amsterdam: John Benjamins.

Karpicke, J. D., \& Roediger, H. L. III (2008). The critical importance of retrieval for learning. Science, 319, 966-968.

Kremmel, B., Brunfaut, T., \& Alderson, J. C. (2017). Exploring the role of phraseological knowledge in foreign language reading. Applied Linguistics, 38(6), 848-870. doi: 10.1093/applin/amv070.

Kweon, S., \& Kim, H. (2008). Beyond raw frequency: Incidental vocabulary acquisition in extensive reading. Reading in a Foreign Language, 20(2), 191-215.

Laufer, B. (2003). Vocabulary acquisition in a second language. Do learners really acquire most vocabulary by reading? Canadian Modern Language Review, 59(4), 565-585.

Laufer, B. (2005). Focus on form in second language vocabulary acquisition. In S. H. FosterCohen, M. P. Garcia-Mayo, \& J. Cenoz (Eds.), EUROSLA Yearbook 5 (pp. 223-250). Amsterdam: John Benjamins.

Laufer, B., \& Girsai, N. (2008). Form-focused instruction in second language vocabulary learning: A case for contrastive analysis and translation. Applied Linguistics, 29(4), 1-23.

Laufer, B., \& Rozovski-Roitblat, B. (2015). Retention of new words: Quantity of encounters, quality of task, and degree of knowledge. Language Teaching Research, 19(6), 687-711. 
Lee, S-K., \& Huang, H-T. (2008). Visual input enhancement and grammar learning: A metaanalytic review. Studies in Second Language Acquisition, 30(3), 307-331.

Levitzky-Aviad, T., \& Laufer, B. (2013). Lexical properties in the writing of foreign language learners over eight years of study: Single words and collocations. In C. Bardel, C. Lindqvist, \& B. Laufer (Eds.), L2 vocabulary acquisition, knowledge and use: New perspectives on assessment and corpus analysis (pp. 127-148). Eurosla Monographs Series 2.

Lewis, M. (1993). The lexical approach. Hove: LTP.

Lewis, M. (1997). Implementing the lexical approach. Hove: LTP.

Lin, C., \& Hirsh, D. (2012). Manipulating instructional method: The effect on productive vocabulary use. In D. Hirsh (Ed.), Current perspectives in second language vocabulary research (pp. 117-148). Bern, Switzerland: Peter Lang.

Lin, P. M. (2012). Sound evidence: The missing piece of the jigsaw in formulaic language research. Applied Linguistics, 33(3), 342-347.

Lindstromberg, S., \& Boers, F. (2008a). Teaching chunks of language. Rum, Austria: Helbling Languages.

Lindstromberg, S., \& Boers, F. (2008b). The mnemonic effect of noticing alliteration in lexical chunks. Applied Linguistics, 29(2), 200-222.

Lindstromberg, S., \& Boers, F. (2008c). Phonemic repetition and the learning of lexical chunks: The mnemonic power of assonance. System, 36(3), 423-436.

Long, M. (1991). Focus on form: A design feature in language teaching methodology. In K. de Bot, R. Ginsberg, \& C. Kramsch (Eds.), Foreign language research in a cross-cultural perspective (pp. 39-52). Amsterdam: John Benjamins.

Martinez, R., \& N. Schmitt (2012). A phrasal expressions list. Applied Linguistics, 33(3), 299320.

McCarthy, M., \& O’Dell, F. (2005). English collocations in use. Cambridge: Cambridge University Press.

Meunier, F. (2012). Formulaic language and language teaching. Annual Review of Applied Linguistics, 32(2), 111-129.

Montero Perez, M., Van Den Noortgate, W., \& Desmet, P. (2013). Captioned video for L2 listening and vocabulary learning: A meta-analysis. System, 41(3), 720-739.

Nassaji, H. (2016). The interactional feedback dimension in instructed second language acquisition. London: Bloomsbury.

Nation, I. S. P. (2014). How much input do you need to learn the most frequent 9,000 words? Reading in a Foreign Language, 26(2), 1-16. 
Nation, I. S. P., \& Webb, S. (2011). Researching and analyzing vocabulary. Boston: Heinle, Cengage Learning.

Paivio, A. (1986). Mental representations: A dual coding approach. New York: Oxford University Press.

Pellicer-Sánchez, A. (2017). Learning L2 collocations incidentally from reading. Language Teaching Research, 21(3), 381-402.

Pellicer-Sánchez, A., \& Schmitt, N. (2010). Incidental vocabulary acquisition from an authentic novel: Do things fall apart? Reading in a Foreign Language, 22(1), 31-55.

Pellicer-Sánchez, A., \& Siyanova-Chanturia, A. (under review). Learning collocations incidentally from reading: A comparison of eye movements in a first and second language.

Peters, E. (2009). Learning collocations through attention-drawing techniques: A qualitative and quantitative analysis. In A. Barfield \& H. Gyllstad (Eds.), Researching collocations in another language: Multiple interpretations (pp. 194-207). Basingstoke: Palgrave Macmillan.

Peters, E. (2012). Learning German formulaic sequences: The effect of two attention-drawing techniques. Language Learning Journal, 40(1), 65-79.

Peters, E. (2016). The learning burden of collocations: The role of interlexical and intralexical factors. Language Teaching Research, 20(1), 113-138.

Peters, E., Hulstijn, J. H., Sercu, L., \& Lutjeharms, M. (2009). Learning L2 German vocabulary through reading: The effect of three enhancement techniques compared. Language Learning, 59(1), 113-151.

Peters, E., \& Pauwels, P. (2015). Learning academic formulaic sequences. Journal of English for Academic Purposes, 20, 28-39.

Pigada, M., \& Schmitt, N. (2006). Vocabulary acquisition from extensive reading: A case study. Reading in a Foreign Language, 18(1), 1-28.

Pulido, D. (2007). The relationship between text comprehension and second language incidental vocabulary acquisition: A matter of topic familiarity? Language Learning, 57(1), 155-199.

Rott, S. (1999). The effect of exposure frequency on intermediate language learners' incidental vocabulary acquisition through reading. Studies in Second Language Acquisition, 21(4), 589-619.

Schmidt, R. (2001). Attention. In P. Robinson (Ed.), Cognition and second language instruction (pp. 3-32). Cambridge: Cambridge University Press.

Schmitt, N. (2010). Researching vocabulary. London: Palgrave Macmillan.

Sharwood-Smith, M. (1993). Input enhancement and instructed SLA: Theoretical bases. Studies in Second Language Acquisition, 15(2), 165-179. 
Sonbul, S., \& Schmitt, N. (2013). Explicit and Implicit lexical knowledge: Acquisition of collocations under different input conditions. Language Learning, 63(1), 121-159.

Steinel, M. P., Hulstijn, J. H., \& Steinel, W. (2007). Second language idiom learning in a pairedassociate paradigm: Effects of direction of learning, direction of testing, idiom imageability, and idiom transparency. Studies in Second Language Acquisition, 29(3), 449-484.

Stengers, H., \& Boers, F. (2015). Exercises on collocations: A comparison of trial-and-error and exemplar-guided procedures. Journal of Spanish Language Teaching, 2(2), 152-164.

Stengers, H., Boers, F., Housen, A., \& Eyckmans. J. (2010). Does chunking foster chunk uptake? In S. De Knop, F. Boers, \& A. De Rycker (Eds.), Fostering language teaching efficiency through cognitive linguistics (pp. 99-117). Berlin and New York, NY: Mouton de Gruyter.

Stengers, H., Boers, F., Housen, A., \& Eyckmans, J. (2011). Formulaic sequences and L2 oral proficiency: Does the type of target language influence the association? International Review of Applied Linguistics in Language Teaching, 49(4), 321-343.

Stengers, H., Deconinck, J., Boers, F., \& Eyckmans, J. (2016). Does copying idioms promote their retention? Computer Assisted Language Learning, 29(2), 289-301.

Szudarski, P. (2012). Effects of meaning- and formed-focused instruction on the acquisition of verb - noun collocations in L2 English. Journal of Second Language Teaching and Research, 1(2), 3-37.

Szudarski, P., \& Carter, R. (2016). The role of input flood and input enhancement in EFL learners' acquisition of collocations. International Journal of Applied Linguistics, 26(2), 245-265

Tekmen, E. A., \& Daloglu, A. (2006). An investigation of incidental vocabulary acquisition in relation to learner proficiency level and word frequency. Foreign Language Annals, 39(2), 220243.

VanPatten, B. (2002). Processing instruction: An update. Language Learning, 52(2), 755-803.

Van Zeeland, H., \& Schmitt, N. (2013). Incidental vocabulary acquisition through L2 listening: A dimensions approach. System, 41(3), 609-624.

Vidal, K. (2011). A comparison of the effects of reading and listening on incidental vocabulary acquisition. Language Learning, 61(1), 219-258.

Webb, S. (2007). The effects of repetition on vocabulary knowledge. Applied Linguistics, 28(1), 46-65.

Webb, S. (2008). The effects of context on incidental vocabulary learning. Reading in a Foreign Language, 20(2), 232-245.

Webb, S., \& Chang, A. (2015). Second language vocabulary learning through extensive reading with audio support: How do frequency and distribution of occurrence affect learning? Language Teaching Research, 19(6), 667-686. 
Webb, S., \& Chang, A. (under review). How does mode of input affect the incidental learning of multiword combinations?

Webb, S., \& Kagimoto, E. (2009). The effects of vocabulary learning on collocation and meaning. TESOL Quarterly, 43(1), 55-77.

Webb, S., \& Kagimoto, E. (2011). Learning collocations: Do the number of collocates, position of the node word, and synonymy affect learning? Applied Linguistics, 32(3), 259-276.

Webb, S., Newton, J., \& Chang, A. (2013). Incidental learning of collocation. Language Learning, 63(1), 91-120.

Winke, P. M. (2013). The effects of input enhancement on grammar learning and comprehension: A modified replication of Lee (2007) with eye-movement data. Studies in Second Language Acquisition, 35(2), 323-352.

Wood, D. (2009). Effects of focused instruction of formulaic sequences on fluent expression in second language narratives: A case study. Canadian Journal of Applied Linguistics, 12(1), 39-57.

Wray, A. (2002). Formulaic language and the lexicon. Cambridge: Cambridge University Press.

Zhang, X. (2017). Effects of receptive-productive integration tasks and prior knowledge of component words on L2 collocation development. System, 66, 156-167. 